\title{
Rearranging Deck Chairs on a Sinking Ship?
}

\author{
Some Reflections on Ethics and Reproduction Looking Back at 2017 \\ and Ahead at 2018
}

\author{
Silvia Camporesi
}

Received: 31 October 2017 / Accepted: 13 December 2017 / Published online: 26 January 2018

(C) Journal of Bioethical Inquiry Pty Ltd. 2018

In the spirit of a "Bioethics Forecast," at the beginning of 2017 I made some predictions for what would keep us bioethicists busy for the rest of the year (Camporesi 2017). Of course, as with most predictions, most of mine missed the mark. As 2017 comes to a close and we prepare to turn the page and welcome the new year, it is worth looking back at some of them to reflect on the main bioethics, and biopolitics, features of this year. Of the ten forecasts I made at the beginning of 2017, in my role as Associate Editor for Ethics and Reproduction I will comment only on those pertaining to reproductive ethics. I will then conclude with some more general reflections on the state of bioethics. Disclaimer: many of the topics below are skewed towards the United Kingdom, the country where I work.

The first prediction I made concerned mitochondrial DNA (mtDNA) replacement technology. Building on the U.K. approval in February 2015 of a new law which allows couples with mitochondrial disorders to use the technology for in-vitro-fertilization (IVF), I was fairly confident that:

Starting from the United Kingdom, we are going to see the first baby born with mitochondrial transfer technology. A reminder, this is the technology that the Human Fertilisation and Embryology Authority (HFEA) approved in February 2015 but only

S. Camporesi $(\square)$

Department of Global Health \& Social Medicine, King's College London, WC2R 2LS, London, UK

e-mail: silvia.camporesi@kcl.ac.uk recently received the Parliamentary go ahead for clinical applications. Last year, the first baby born with mitochondrial transfer technology occurred in Mexico and sparked a debate. In addition to the technology's use in avoiding transmission of mitochondrial disorders, it will probably be used to allow gay couples (of both sexes) to have a child genetically related to both. (Camporesi 2017)

I was wrong about the first baby being born with the technology in the United Kingdom, as that has not been the case. However, the debate about whether mtDNA replacement technology should be available for others (such as lesbian couples) devoid of a "therapeutic reason" has begun (Palacios-González and MedinaArellano 2017a, b; Rulli 2017; Liao 2017). Cavaliere and Palacios-González have spearheaded this discussion (Cavaliere and Palacios-González forthcoming) and argued that it would be ethically unjustifiable to allow couples at risk of transmitting a mtDNA disease to access the technology, while forbidding its access to lesbian couples. Cavaliere had also previously pointed out the dangers of moral colonialist positions apparent in reactions from other "more developed" countries to the birth of the first baby born with this technology in Mexico (Cavaliere 2016), while Palacios-González and Medina-Arellano, both originally from Mexico, countered the claim that Mexico is a "free for all" place where any kind of research can be carried out by pointing out that Mexican regulations pertaining to assisted reproduction in fact do apply to MRTs, even if they were written for regulating infertility research (Palacios-González and Medina-Arellano 2017a, 2017b). 
Meanwhile, the United Kingdom has historically prided itself on its regulatory apparatus of assisted reproduction and embryo research and has been dismissive of research being conducted outside the HFEA framework. Underlying economic and financial reasons pertaining to the drive to innovate should not be discounted when analysing the robust political and ethical support that the United Kingdom has offered to new technologies such as mtDNA replacement technologies and CRISPR genome editing. Such reasons underlie also, at least in part, the first announcement to apply CRISPR on human embryos, made in September 2015 by U.K.-based scientist Kathy Niakan. At the beginning of 2017, I wrote:

The recently inaugurated Francis Crick Institute in London will see the first applications of CRISPR genome editing in human embryos by the group led by Kathy Niakan, for which she received the go-ahead in February 2016. In Europe, the momentum around CRISPR research on human embryos is building, with other countries moving ahead with their own regulations on CRISPR's use in human embryos (for example, Sweden). Beyond Europe, we may see clinical applications of the technology in China, with potential transfer of CRISPR-edited human embryos to the uterus. (Camporesi 2017)

That has indeed been the case, with Kathy Niakan publishing her research outlining the role of OCT4 factor in early embryogenesis in the journal Nature (Fogarty et al. 2017). Reflecting on this research from a sociological point of view, I note how interesting it is that scientists seem to always have to justify research on human embryos in terms of learning more about the causes of miscarriage and infertility (note, this is also how Kathy Niakan framed her research when applying for a licence to the HFEA [HFEA 2016]). Why, we should ask, do we need scientists to frame the benefits of this research in such terms? In my opinion, this is a way of "strategic naturalizing" the research, i.e. couching the research in terms that are appealing to the public (the term "strategic naturalizing" was originally developed by Charis Thompson in her 2005 book, in relation to the early years of IVF). However, I think that we should unpack these naturalizing strategies, and we should question our responsibilities as a society in coproducing this kind of rationale for research on human embryos. What if we could expand the justification of said research to include shedding light on the early development of human embryos outside the human body, about which we know very little? Or what if we said that research on human embryos is particularly interesting as it could illuminate the potentialities of ectogenesis, i.e. of growing an embryo (later, a foetus) outside the human body?

Speaking of embryo research beyond fourteen days, I wrote at the beginning of 2017 :

Again in the United Kingdom, we may see a new parliamentary commission take up the debate on extending research on human embryos past the current limit of fourteen days. A recent conference organized by Progress Educational Trust in London in December 2016 discussed the proposal. However, no decision will be made in 2017. (Mary Warnock's commission took five years to produce a recommendation, which was not enshrined into law until several years later.) (Camporesi 2017)

The Parliamentary Commission that I had predicted has not come into place yet, but the proverbial ball is indeed rolling. The Nuffield Council on Bioethics (which is the closest equivalent in the United Kingdom to a deliberative bioethics body) published a Human Embryo Culture Report in August 2017, which includes a background report by Elves and McGuinness on the controversial topic of the moral status of the human embryo, and several replies from leading UK scientists and philosophers and bioethicists (Nuffield Council of Bioethics 2017b). The report asks the question: Is new research destabilizing the fourteen day rule? The answers change depending on how the fourteen day rule is understood. Many, including the Chair of the IVF Inquiry that led to the establishment of the rule in 1990, Baroness Mary Warnock, considered it as a "compromise" between irreconcilable moral positions (Wilson 2011, 2014). Others, however, such as philosopher David Jones, Director of the Catholic-based Anscombe Centre in Oxford, question whether it was a compromise in the first place. Referring to the fact that only in 2016 have scientists been able to culture embryos in vitro for close to fourteen days (Deglincerti et al. 2016; Shahbazi et al. 2016), hence triggering the discussion of the rule, Jones writes:

A rule that "could not be breached" is not a "rule", and is certainly not a "compromise". Speed limits are compromises, but a speed limit faster than anyone could drive is not a compromise, nor 
indeed is it a rule in any meaningful sense. The 14day "rule" functions to give reassurance by means of an empty prohibition. It is part of a disingenuous political settlement. (Nuffield Council of Bioethics 2017b, 69)

While I do not agree with Jones' philosophical position on the status of the human embryo, I could not refrain from finding convincing his comparison between the fourteen day rule and a speed limit that could not, from a technical point of view, be breached. In her response to the background paper by Elves and McGuinness, philosopher Elseljin Kingma (Nuffield Council of Bioethics 2017b, 73-78) points out a missing element of the discussion on the moral status of the embryo, i.e. that not only do intrinsic elements pertain to the definition of moral status but so do extrinsic elements, such as the context (or "location") in which the embryo finds itself (i.e. a womb, a Petri dish, etc), and the willingness of the mother to carry out that pregnancy. Both elements affect the moral status and value of the embryo, as the moral status and value of the embryo depend on a potentiality that is determined by extrinsic factors. Perhaps it could be helpful to think back on the etymology of the word "person": in ancient Rome, a "persona" was the mask worn at theatre (since of course only free men could perform, not women, nor slaves), and the same actor would change role depending on the "persona" he wore. That is what happens, too, with the moral status of the embryo or foetus: depending on the location it finds itself in, and on the willingness of a woman to carry a pregnancy to term, its moral status is affected. This is what Australian philosopher Catherine Mills calls the "performative" elements of the concepts of moral status and personhood (Mills 2013).

Overall, new research leading to the possibility of culturing embryos in vitro for a longer term (Deglincerti et al. 2016; Shahbazi et al. 2016) and of creating synthetic embryo-like structures (Aach et al. 2017) are re-opening a discussion of the limits of these technologies. I am of the opinion that technical feasibility will eventually drive a change in law-that does not mean necessarily that I think this is a desirable outcome, only that I think the technical feasibility view (when something is possible, somebody, somewhere, will do it) will eventually prevail. Others, like Cavaliere, have argued that technical feasibility alone should not drive a change in law, as "appealing to the beneficence of research and to its technical feasibility is more problematic than those in favour of extending the limit for embryo research suggest it is," first and foremost because the appeal to beneficence relies on "an optimistic view of scientific progress, research and technologies" (Cavaliere 2017, 7) and secondly because it leads to a misleading calculation of costs and benefits, where the benefits are understood as benefits to society but the costs are costs only on human embryos.

The last point I made at the beginning of the year within the context of reproductive ethics was an "easy"-given the premises-prediction that noninvasive prenatal testing (NIPT) was going to become a "hot topic" for discussion in bioethics circles and beyond in the United Kingdom:

The United Kingdom will see the establishment of non-invasive prenatal testing (NIPT) through the National Health System (NHS). These are simple blood tests performed within the first ten weeks of pregnancy to detect chromosomal abnormalities, and likely in the near future they could be coupled with whole-genome sequencing. The United Kingdom is the first country where NIPT will be offered not only by commercial companies (like in the United States) but as part of a national health service's prenatal screening. There is a worry that NIPT will lead to an increased rate of terminations for people with Down's syndrome, and the bioethical discussions will be around what counts as a disability, what counts as a difference, and what kind of society we want to live in. The Nuffield Council on Bioethics is working on this and has launched a project to incorporate the perspectives of people with Down's syndrome. (Camporesi 2017)

This has indeed been the case, and the Nuffield Council on Bioethics has again spearheaded this research and carried out a unique qualitative study of the views of people with Down Syndrome (Nuffield Council of Bioethics 2017a). The study has found that people with Down Syndrome feel threatened by the implementation of a screening which is presented to them as potentially leading to the eradication of their condition (as in the BBC Documentary "A World Without Down Syndrome?" aired for the first time in November 2016 and directed by British actress Sally Phillips, mother of a child with Down Syndrome) (Phillips, 2016). I think, however, that this way of presenting the test could potentially be misleading and also that there might be some confusion about the way the NHS is planning to implement the screening. Let me explain. 
NIPT stands for "non-invasive prenatal testing" and can detect trisomies with very high accuracy (higher than 99 per cent for Trisomy 21 or Down Syndrome; higher than 97 per cent for trisomy 18 and 22, [Taylor-Phillips et al. 2016]), on the basis of a ratio of foetal to maternal DNA circulating in the mother's blood. It is called NIPT instead of NIPD ("test"instead of "diagnosis") as a positive result is followed by an amniocentesis - an invasive test for trisomies that typically follows a combined screening test if the results indicated a high risk for trisomies - to confirm the positivity of the test. Private clinics in the United Kingdom and elsewhere routinely offer NIPT as early as nine or ten weeks (at which point there is sufficient circulating cell free foetal DNA to be able to calculate the ratio). For its part, the NHS are offering NIPT after the so-called "combined test" which is routinely offered in the United Kingdom as a screening test to all women between twelve and thirteen weeks - the combined test is based on an algorithm combining the result of nuchal translucency measurement and two maternal blood test parameters to calculate the relative risk of carrying a foetus affected by a chromosomal abnormality, and having an accuracy of respectively 90, 97 and 92 per cent for detecting trisomies 21, 18, and 22 (Santorum et al. 2017). It seems to me that offering NIPT after the combined test somewhat defeats the main purpose (or one of the main purposes) of the NIPT test itself, which is to test early. The likely result, in my opinion, of the late introduction of NIPT is that women who are diagnosed as having a high risk at the combined screening test will be called for a "second level" test - the NIPT — at around fourteen weeks. This will mean, in practice, that they are likely not to receive the results of the NIPT test until the fifteenth week of pregnancy. While this, from a public health perspective, could still be thought of as a positive outcome, as the number of subsequent amniocenteses would be reduced (only those women positive at the NIPT will go for an amniocentesis), the same cannot be said from the point of view of the pregnant women, as a positive result at the NIPT as a second level test will not only create high anxiety for weeks following a "high risk" outcome of the combined screening test but also initiate a cycle of stressful medical testing (see Chris Kaposy and his personal narration of the irresistibility of technology, with one test after the other [Kaposy 2013]).

Why, one must ask, has the NHS decided to implement NIPT in this way? Was it a compromise as a result of fear of increased likelihood that mothers would terminate if a more accurate test is offered earlier? If that were the case, it would show, I'd venture to say, little trust in the decisional capacities of women, and puts them in a condition where they are forced to make very difficult decisions in case of a positive test for trisomy 21 or another chromosomal abnormality later in the pregnancy. It is difficult not to see a paternalistic intervention behind the decision to offer NIPT as a second level test. I should add that, as I am writing this editorial I am expecting my first child, and I bought NIPT commercially for myself at nine weeks. I took the test because I did not want to wait until twelve weeks for the combined test. For cultural reasons, the standard of twelve to fourteen weeks in the United Kingdom for a first scan and combined test seems to me, as an Italian, to come surprisingly late (in Italy the protocol of the Italian National Health System, Sistema Sanitario Nazionale, includes a first, free of charge, scan at seven to eight weeks, for all women). I believe that what counts as "risk" should not be equated only with invasive or non-invasive or with increased or not increased likelihood of termination. Indeed, the test should be more appropriately called "cell free foetal DNA test" or "prenatal cell-free DNA screening", as it has started to be called in some contexts. I am of the opinion that women are not going to take lightly the decision to have an abortion, ever, and that NIPT, if introduced, should be introduced earlier and replace the combined test. ${ }^{1}$

Moving away from embryo research and reproductive ethics and broadening the gaze towards broader biopolitical international issues, I had made another "easy" prediction in reference to the vacancy left by the death of Justice Antonin Scalia to the Supreme Court in the United States:

Moving across the pond to the United States, President Obama's Presidential Commission for the Study of Bioethical Issues reached the end of its road. It will be interesting to see whether new U.S. President Donald Trump will call for a new commission on bioethics. It is not a given that each president establishes a bioethics commission, although the past two presidents have done so. If that is the case, bets are open as to who might be chair. For sure we are going to see old (beginning of life, women's reproductive rights, end of life) and new (CRISPR genome editing technology, synthetic

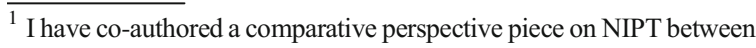
the United Kingdom, China, Italy, and Brazil, (Zeng et. al. 2016).
} 
biology) issues in bioethics on the table for debate. [...] Perhaps more importantly (because it of its longer-lasting impacts) will be the Trumpappointed new member(s) of the U.S. Supreme Court. There is currently one vacancy (following the death of Justice Antonin Scalia in 2016), but it is expected that one or two more judges will retire in the next few years. (Camporesi 2017)

2017 has seen the appointment of Neil Gorsuch to the U.S. Supreme Court in April, who is now the youngest Justice on the U.S. Supreme Court (he is fifty now, was only forty-nine when appointed). Gorsuch is widely regarded as a conservative and his appointment tilted the balance of the Court to a five to four (or possibly six to three, with Justice Roberts being the "swing vote", but siding often with more conservative justices) conservative split. To date there is still no Presidential Commission on Bioethics, and it is doubtful that President Trump will call for one, after dismantling other expert-based committees in 2017 (on climate change, ${ }^{2}$ business, ${ }^{3}$ and infrastructure ${ }^{4}$ ).

While it is difficult to speculate why that might be the case, it is perhaps reflecting a broader distrust of experts which extends well beyond the walls of the White House and afflicts scientists and experts in a wide array of disciplines. With Dr. Maria Vaccarella (Bristol University, United Kingdom) and Professor Mark Davis (Monash University, Australia) we discussed some of the questions of public trust in expert knowledge in the special issue we curated for this journal, which was published in February 2017 and included contributions ranging from the resistance to vaccinations, to markets of egg donors, to the controversial diagnosis of gestational diabetes and chronic pain, and to distrust in healthcare and healthcare professionals in general (Attwell et al. 2017; Bowman 2017; Buchman, Ho, and Goldberg 2017; Edwell and Jack 2017; Wong 2017). In our contribution, we noted that across a range of contexts, the increasing distrust in expert knowledge raises significant epistemological questions about the nature of expertise itself (Camporesi, Vaccarella and Davis 2017). Bioethics, which was born to assuage mistrust in medical care, is now part of the problem (Rich 2017). While we of course could not solve the

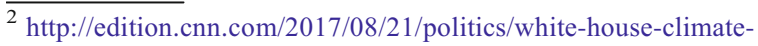
change-committee-dismantled/index.html

${ }^{3}$ https://www.theguardian.com/us-news/2017/aug/16/donald-trumpadvisory-councils-disbanded-ceos-charlottesville

${ }^{4}$ http://fortune.com/2017/08/17/donald-trump-infrastructure-councilcanceled /
}

problem of why there is an increasing distrust in expert knowledge (we do suspect the answer will need to be context based), in our special issue we highlighted different factors that might contribute to this distrust, such as "epistemic chasms, knowledge hierarchies, and a deferral and avoidance of uncertainty" (Camporesi, Vaccarella and Davis 2017,29). Perhaps we should have added "academic-speak" to our list ...

To conclude, 2017 has been a year dominated by the re-opening of the vexed discussion of the moral status of the embryo, by the value of the fourteen day limit on research on human embryos as a valid "compromise" for international policy regulation, by the discussion of the "societal justifiability" of genome editing technologies such as CRISPR or mitochondrial replacement techniques coupled with IVF technologies. 2018 promises to be an exciting year for bioethics, medical ethics, and law and ethics, especially since the beginning of a new term for the U.S. Supreme Court on October 2017, in which the justices have agreed to hear thirty-three cases, including battles over gun rights, sexual-discrimination, privacy and security, religious freedom and alien rights (Slattery 2017). Other issues with which we have been familiar for years will re-emerge as contested issues in 2018. For example, abortion is going to feature prominently, with some high-profile cases on both sides of the pond. The Northern Ireland abortion ban is currently being challenged, at the time of writing this piece, in front of the U.K. Supreme Court, while the promulgation of an increasing number of state-based foetal protection laws in the United States seems to threaten women's right to have an abortion (Meredith 2016).

It seems therefore that there are old and new ethical issues on the table, with plenty of issues for bioethicists to engage with. As bioethicists, we need to pursue our work with a rigor and focus that strengthens our legitimacy beyond the pages of bioethics journals. Paraphrasing from Leif Oxburgh, scientist and principal investigator leading a molecular medicine laboratory at Maine Medical Centre Research Institute (MMRCI) in Portland, ME, ${ }^{5}$ sometimes bioethicists may appear to scientists, or to those outside the field, to be "re-arranging the deck chairs on a sinking ship." I received this comment after giving a talk at MMRCI on the ethical challenges posed by the applications of CRISPR genome editing to human embryos in the summer of 2017. I had not realized, at that time, that a

\footnotetext{
${ }^{5}$ Personal Communication, August 21, 2017. I acknowledge Leif Oxburgh for kindly granting me permission to quote him in this editorial.
} 
talk given to scientists outlining the ethical challenges raised by the uses of CRISPR genome editing on human embryos might come across as "re-arranging the chairs" on a "sinking ship." Out of metaphor, the discussion about the vexed status of the human embryo, and a similar discussion about the fourteen day limit for research on human embryos, could be equated to "re-arranging the deck chairs"; while the untouched background discussions on a right (or not) to universal healthcare, and the question of public trust in expert knowledge with its manifold ramifications, could be equated to the "sinking ship." In short, are we-as bioethicists-merely rearranging deck chairs on a sinking ship with our arguments, instead of trying to save the ship from sinking? I, for one, will carry this question forward with me as we embark on the coming year.

\section{References}

Aach, J., J. Lunshof, E. Iyer, and G.M. Church. 2017. Addressing the ethical issues raised by synthetic human entities with embryo-like features. Elife 6: e20674.

Attwell, K., J. Leask, S.B. Meyer, P. Rokkas, and P. Ward. 2017. Vaccine rejecting parents' engagement with expert systems that inform vaccination programs. Journal of Bioethical Inquiry 14(1): 65-76.

Bowman, D. (2017). The moral of the tale: Stories, trust, and public engagement with clinical ethics via radio and theatre. Journal of Bioethical Inquiry 14(1): 43-52.

Buchman, D.Z., A. Ho, and D.S. Goldberg. 2017. Investigating trust, expertise, and epistemic injustice in chronic pain. Journal of Bioethical Inquiry 14(1): 31-42.

Camporesi, S. 2017. Bioethics forecast 2017. Journal of Bioethical Inquiry Blog http://bioethicalinquiry.com/bioethics-forecast2017/. Accessed December 19, 2017.

Camporesi, S., M. Vaccarella, and M. Davis. 2017. Investigating public trust in expert knowledge: Narrative, ethics, and engagement. Journal of Bioethical Inquiry 14(1): 23-30.

Cavaliere, G. and C. Palacios-González. Forthcoming. Lesbian motherhood and mitochondrial replacement techniques: Reproductive freedom and genetic kinship. Journal of Medical Ethics.

Cavaliere, G. 2016. The Mexican mitochondrial case and moral supremacy. Bionews http://www.bionews.org. uk/page_711486.asp. Accessed December 19, 2017.

. 2017. A 14-day limit for bioethics: The debate over human embryo research. BMC Medical Ethics 18(1): 38.

Deglincerti, A., G.F. Croft, L.N. Pietila, M. Zernicka-Goetz, E.D. Siggia, and A.H. Brivanlou. 2016. Self-organization of the in vitro attached human embryo. Nature 533(7602): 251254.

Edwell, J., and J. Jack. 2017. Gestational diabetes testing, narrative, and medical distrust. Journal of Bioethical Inquiry 14(1): 53-63.
Fogarty, N.M., A. McCarthy, K.E. Snijders, et al. 2017. Genome editing reveals a role for OCT4 in human embryogenesis. Nature 550(7674): 67-73.

HFEA 2016 Minutes of Licence Committee on Kathy Niakan's Application to use CRISPR on human embryos. http://hfeaarchive.uksouth.cloudapp.azure.com/www.hfea. gov.uk/10187.html Accessed December 19, 2017

Kaposy, C. 2013. A personal experience of prenatal testing for Down syndrome. Narrative Inquiry in Bioethics 3(1): 1821.

Liao, S.M. 2017. Do mitochondrial replacement techniques affect qualitative or numerical identity? Bioethics 31(1): 20-26.

Meredith, S. 2016. Policing pregnancy: The law and ethics of obstetric conflict. London and New York: Routledge.

Mills, C. 2013. The performativity of personhood. Journal of Medical Ethics 39(5): 325-325.

Nuffield Council on Bioethics. 2017a. Consultation with individuals with Down Syndrome about non-invasive prenatal testing. http://nuffieldbioethics.org/wp-content/uploads/Barter report_on_NIPT.pdf. Accessed December 19, 2017.

- 2017b. Human embryo culture report: Discussions concerning the statutory time limit for maintaining human embryos in culture in the light of some recent scientific developments. http://nuffieldbioethics.org/wpcontent/uploads/Human-Embryo-Culture-web-FINAL.pdf. Accessed December 19, 2017.

Palacios-González, C., and M.D.J. Medina-Arellano. 2017a. Mitochondrial replacement techniques and Mexico's rule of law: On the legality of the first maternal spindle transfer case. Journal of Law and the Biosciences 4(1): 50-69.

- 2017b. Author's response to peer commentaries: Mexico's rule of law and MRTs. Journal of Law and the Biosciences. https://doi.org/10.1093/jlb/lsx031.

Phillips, S. 2016. A world without Down Syndrome? BBC Documentary, http://www.bbc.co.uk/programmes/b07ycbj5 Accessed December 19, 2017.

Rich, L.E. 2017. Prestidigitation vs. public trust: Or how we can learn to change the conversation and prevent powers from "organizing the discontent". Journal of Bioethical Inquiry 14(1): $1-6$.

Rulli, T. 2017. The mitochondrial replacement "Therapy"myth. Bioethics 31(5): 368-374.

Santorum, M., D. Wright, A. Syngelaki, et al. 2017. Accuracy of first-trimester combined test in screening for trisomies 21, 18 and 13. Ultrasound in Obstetrics \& Gynecology 49(6), 714 720 .

Shahbazi, M.N., A. Jedrusik, S. Vuoristo, et al. 2016. Selforganization of the human embryo in the absence of maternal tissues. Nature Cell Biology 18(6): 700-708.

Slattery, E. 2017. Overview of the Supreme Court's 2017-2018 term. The Heritage Foundation, September 5. http://www. heritage.org/courts/report/overview-the-supreme-courts2017-2018-term. Accessed December 19, 2017.

Taylor-Phillips, S., K. Freeman, J. Geppert, et al. 2016. Accuracy of non-invasive prenatal testing using cell-free DNA for detection of Down, Edwards and Patau syndromes: A systematic review and meta-analysis. BMJ Open 6(1): e010002. 
Thompson, C. 2005. Making parents: The ontological choreography of reproductive technologies. Cambridge, Massachusetts, and London, England: MIT press..

Wilson, D. 2014. The making of British bioethics. Manchester: Manchester University Press.

Wilson, D. 2011. Creating the 'ethics industry': Mary Warnock, in vitro fertilization and the history of bioethics in Britain. BioSocieties 6(2): 121-141.
Wong, K.A. 2017. Donor conception and "passing," or; Why Australian parents of donor-conceived children want donors who look like them. Journal of Bioethical Inquiry 14(1): $77-$ 86.

Zeng, X., L. Zannoni, I. Löwy, and S. Camporesi. 2016. Localizing NIPT: Practices and meanings of non-invasive prenatal testing in China, Italy, Brazil and the UK. Ethics, Medicine and Public Health 2(3): 392-401. 